\title{
Development of the Vascular Supply in the Dental Pulp of Rat Molars - Scanning Electron Microscope Study of Microcorrosion Casts -
}

\author{
By
}

\author{
Shigemitsu YOSHIDA, Hayato OHSHIMA and Shigeo KOBAYASHI \\ 2nd Department of Oral Anatomy, Niigata University School of Dentistry, \\ 2-5274 Gakkocho-dori, Niigata 951, Japan \\ (Chief: Prof. S. Kobayashi)
}

- Received for Publication, July 22, 1988-

\begin{abstract}
Key words: Dental pulp, Microvasculature, Tooth development, Dentinogenesis, Vascular cast
Summary: The developmental changes of the vascular supply in the dental pulp were studied in molars of rats from the 19-day embryo to 21 days after birth employing the vascular casting/scanning electron microscope method. In the 19-day embryo, terminal pulpal capillaries were observed in the inner region of the dental papilla and formed a coarse, flattened vascular network consisting of thick capillaries. With the beginning of dentinogenesis, the terminal pulpal capillaries invaded into the odontoblastic layer forming hairpin-like loops and narrowing their lumina. At 21 days after birth, they formed a dense, flattened vascular network consisting of thin capillaries between the odontoblasts, only about $5 \mu \mathrm{m}$ from the predentin. These findings indicate that the terminal pulpal capillaries play an active role in dentin formation.
\end{abstract}

Since the nutritional importance of the blood vessels in the dental pulp for the production of dentin matrix and its subsequent calcification is obvious, many researchers have investigated the distribution of pulpal capillaries by various methods. The vascular architecture of the dental pulp has been examined primarily by light microscopy with injection of dyes $1,2,4,5,8,9,11,15,16,19)$, radiopaque medium ${ }^{3,20)}$ or latex silicone ${ }^{13)}$. However, the three-dimensional microvascular architecture of the pulpal vessels had not yet been fully elucidated due to the limited resolution and shallow focus inherent to light microscopy.

Recently, the vascular casting method, which was first introduced by Taniguchi et al. $\left(1952^{26)}, 1955^{27)}\right.$ ) for scanning electron microscope studies on blood vessels, has been widely applied to various organs. As a result, many investigators have been able to examine the three-dimensional microvasculature of the dental pulp, e.g. in the $\operatorname{dog}^{14,24)}$, rat incisor ${ }^{21)}$ and rabbit incisor ${ }^{18)}$, but more detailed studies on the developmental changes of the pulpal vessels are not yet available.

The present study was therefore undertaken to clarify the three-dimensional microvascular changes of the terminal pulpal capillary networks in the developing molar teeth of rats.

\section{Materials and Methods}

Ten pregnant female Wistar rats were used. The onset of pregnancy was determined by vaginal smearing, the day of finding sperm in the smear being called day 0 in the dating of 
all embryos, and the day of birth being called day 0 in the dating of all infants. In this way, day 19 and 21 fetuses and day 1, 5 and 21 infants were obtained.

The animals were anesthetized with pentobarbital sodium and perfused through the ascending aorta with Ringer solution followed by $4 \%$ paraformaldehyde in $0.1 \mathrm{M}$ phosphate buffer (pH. 7.4). Mercox (Dainippon-ink Co., Ltd.), which had been diluted with $25 \%$ monomeric methyl methacrylate ester ${ }^{17}$, was then injected under moderate pressure (ca. $10 \mathrm{ml} / \mathrm{min}$ ). After the animals had been left at room temperature for $5 \mathrm{hrs}$ to allow the resin to polymerize, the upper jaws were removed with a razor blade. They were then digested with $20 \% \mathrm{KOH}$ at $40^{\circ} \mathrm{C}$ for $24 \mathrm{hrs}$. Some specimens were decalcified with $1 \mathrm{~N} \mathrm{HCl}$ before digestion. The cast specimens were washed thoroughly in running tap water for $12 \mathrm{hrs}$ and freeze-dried. After drying, the casts were mounted on specimen holders with a conductive silver paint (Dotite) and dissected under an optical stereoscope using sharpened needles and forceps to expose the dental pulp for observation. The dissected specimens were coated with gold in an ion sputter coater (IB-3, Eiko) and examined under a scanning electron microscope (S-510, Hitachi) at an accelerating voltage of $5-10 \mathrm{KV}$.

Some animals were perfused with $2.5 \%$ glutaraldehyde in $0.1 \mathrm{M}$ phosphate buffer and semi-thin sections stained with toluidine blue were also prepared in the usual manner.

\section{Findings}

Fig. 1 shows a sagittal semi-thin section of the dental papilla of the upper first molar teeth in a 19-day embryo. The tooth germ was at the early bell stage of tooth development. The cells of the inner and outer enamel epithelium, stellate reticulum, stratum intermedium, dental papilla and dental follicle could be clearly distinguished, whereas no differentiation of ameloblasts or odontoblasts had yet taken place. Capillaries were observed in the inner region of the dental papilla and appeared to have no relation to the mesenchymal cells situated in close proximity to the inner enamel epithelium. The terminal pulpal vessels formed a coarse, flattened vascular network consisting of thick capillaries, 20-30 $\mu \mathrm{m}$ in diameter in the cast, and two pulpal horns were prominent (Fig. 2).

In the 21-day embryo, with the beginning of differentiation of the inner enamel epithelium to ameloblasts, mesenchymal cells situated in close proximity to the inner enamel epithelium began to differentiate into odontoblasts, but deposition of organic substances had not started by that time. The terminal pulpal capillaries gradually approached the odontoblasts (Fig. 3). The terminal capillary network increased in extent and five pulpal horns were clearly recognized. The density of the network was higher and the diameter of the capillaries in the cast (15-20 $\mu \mathrm{m})$ was thinner than that in the 19-day embryo (Fig. 4).

By the 1st day after birth, dentinogenesis and amelogenesis had already commenced in the cuspal region, where terminal pulpal capillaries showed invasion into the odontoblastic layer (Fig. 5). The arterioles, after branching out a few times near the surface of the dental pulp, proceeded to the terminal pulpal capillaries. The surface of the vascular network was irregular due to many low capillary loops towards the predentin. The diameter of the capillaries in the cast (about $10 \mu \mathrm{m}$ ) was thinner than that in the 21-day embryo (Fig. 6).

By 5 days after birth, amelogenesis and dentinogenesis had progressed in all regions of the tooth crown. Terminal pulpal capillaries were found in the odontoblastic layer, only about $5 \mu \mathrm{m}$ from the predentin (Fig. 7). The vascular network again became flattened and 
formed a dense network consisting of thin capillaries, about $5 \mu \mathrm{m}$ in diameter in the cast (Fig. 8).

At 21 days after birth, the upper first molar teeth had just erupted into the oral cavity. The terminal pulpal capillaries were situated in the same position as at 5 days after birth, about $5 \mu \mathrm{m}$ from the predentin. The shape of the network and the diameter of the capillaries in the cast resembled those at 5 days after birth, but the density of the network was apparently higher than that at 5 days (Fig. 9). The arterioles, after branching out a few times near the surface of the dental pulp, proceeded to the terminal pulpal capillaries, similarly to those on the 1st day after birth (Fig. 10).

\section{Discussion}

Positional changes of the terminal pulpal capillaries in the developing molar teeth of rats were first described by Bernick (1960) ${ }^{4}$ using the India ink perfusion method. He reported that the blood vessels were located in the pulpal odontoblastic border of the dental papilla at the bell stage of tooth development, and with the beginning of dentinogenesis, they penetrated the odontoblastic zone and formed a network at the predentin border.

In the present study, positional changes of the terminal pulpal capillaries were also confirmed, but the capillaries were situated in the inner region of the dental papilla at the early bell stage of tooth development and appeared to have no relation to the mesenchymal cells located in close proximity to the inner enamel epithelium. With the beginning of dentinogenesis, the terminal capillaries approached the odontoblasts, invaded the odontoblastic layer and finally became located close to the predentin, at about only $5 \mu \mathrm{m}$.

The terminal vascular network first consisted of thick capillaries, but they became progressively thinner with advance of dentin formation. The density of the network gradually increased with the invasion into the odontoblastic layer. These findings indicate that the terminal capillary network plays an active role in dentin formation.

Invasion of terminal pulpal capillaries into the odontoblastic layer has been reported in the rat incisor ${ }^{1,8,22,23,25)}$, rat molar ${ }^{4,5,8,12)}$, mouse molar), $\operatorname{dog}^{9,16)}$, cat $^{2,6,11)}$, rabbit $^{18)}$ and $\operatorname{man}^{15,19)}$. Among these reports, Bernick $(1962)^{5)}$ demonstrated that the terminal pulpal capillaries gradually withdrew from the predentin border to the odontoblastic-pulpal border with advancing age. On the other hand, Hoffman and Schour $(1940)^{10)}$ investigated the rate of apposition of the dentin in the molar teeth of rats, and found there was a marked decrease in the daily rate from $16 \mu \mathrm{m}$ in weanlings to 1 to $2 \mu \mathrm{m}$ in old animals. These findings also strongly suggest that the capillaries in the odontoblastic layer offer a rapid and sufficient supply of metabolic substances necessary for dentinogenesis.

The surface structure of the terminal capillary network varied from flat to irregular and then again to flat with advance of dentin formation. It is suggested that the surface irregularity reflected an invading process of the capillaries into the odontoblastic layer. On the other hand, Takahashi et al. (1982) ${ }^{24)}$ and Kobayashi (1983) ${ }^{14)}$ clearly demonstrated that the terminal vascular network in the dog was composed of three layers: a terminal capillary network, capillary network and venular network. Semba et al. (1983) ${ }^{21)}$ also described a three-layered structure in the rat incisor. However, we could not distinguish these layers in rat molar teeth in the present study. This may be related to the calcification rate during dentin formation.

\section{References}

1) Adams, D.: Peripheral capillaries in the rodent incisor pulp. J. Dent. Res., 38: 969-978, 1959. 
2) Adams, D.: The blood supply to developing dentine. Archs. oral Biol., 7: 773-774, 1962.

3) Aoyagi, F.: Microangiogram of human dental pulp vessels. Bull Tokyo Dent. Coll., 5: 59-69, 1964.

4) Bernick, S.: Vascular supply to the developing teeth of rats. Anat. Rec., 137: 141-151, 1960.

5) Bernick, S.: Age changes in the blood supply to molar teeth of rats. Anat. Rec., 144: 265-274, 1962.

6) Bishop, M.A.: An investigation of pulp capillaries and tight junctions between odontoblasts in cats. Anat. Embryol., 177: 131-138, 1987.

7) Corpron, R.E., Avery, J.K. and Lee, S.D.: Ultrastructure of terminal pulpal blood vessels in mouse molar. Anat. Rec., 179: 524-542, 1974.

8) Garfunkel, A. and Sciaky, I.: Vascularization of the periodontal tissues in the adult laboratory rat. J. Dent. Res., 50: 880-887, 1971.

9) Goto, T.: On the distribution of the blood capillaries in the oral cavity and its surroundings. Part 4. Teeth and its surroundings of the dog. Hiroshima Igaku, 11: 550-561, 1958. (in Japanese).

10) Hoffman, M.M. and Schour, I.: Quantitative studies in the development of the rat molar. I. The growth pattern of the primary and secondary dentin (from birth to 500 days of age). Anat. Rec., 78: 233-251, 1940.

11) James, W.W.: The blood capillary system of the odontoblast layer of the dental pulp. J. Anat., 89: 574-549, 1955.

12) Josephsen, K., Fejerskov, O. and Theilade, J.: Age changes in juxtaodontoblastic capillaries of rat molars. Scand. J. Dent. Res., 82: 574-578, 1974.

13) Kindlová, M. and Meterna, V.: Blood vessels of the rat molar. J. Dent. Res., 41: 650-660, 1962.

14) Kobayashi, M.: A scanning electron microscope study of the blood vessels of dog pulp using corrosion resin casts. Kanagawa Shigaku, 18: 173-199, 1983. (in Japanese).

15) Kramer, I.R.H.: The vascular architecture of the human dental pulp. Archs. Oral Biol., 2: $177-189,1960$.

16) Nakamura, T.: On the minute blood vessel and fibrillar connective tissue in the teeth and their surrounding tissue. Mie Igaku, 4: 2399-2410, 1960. (in Japanese).

17) Ohtani, O. and Murakami, T.: Peribiliary portal system in the rat liver as studied by the injection replica scanning electron microscope method. SEM/1978/II, 241-244, SEM Inc., AMF O'Hare, 1978.

18) Okada, S., Ohta, Y., Tokioka, T., Kuramae, K. and Lin, R.T.: Microvascular patterns of the dental pulp of the upper major incisor of the rabbit. Okajimas Folia Anat. Jpn., 63: 255-264, 1986.

19) Provenza, D.V.: The blood vascular supply of the dental pulp with emphasis on capillary circulation. Circ. Res., 6: 213-218, 1958.

20) Saunders, R.L. de C.H.: Microangiographic studies of periodontic and dental pulp vessels in monkey and man. J. Canad. Dent. Ass., 33: 245-252, 1967.

21) Semba, T., Tabata, S. and Yamamoto, H.: The three dimensional structure of the vascular system in the rat lower incisor employing the plastic casting method. Med. J. Kagoshima Univ., 35: 141-152, 1983. (in Japanese).

22) Tabata, S. and Semba, T.: Observation on blood capillaries in the rat incisor pulp. Jpn. J. Oral Biol., 27: 1055-1064, 1985. (in Japanese).

23) Tabata, S. and Semba, T.: Examination of blood capillaries in rat incisor pulp by TEM of thin sections and freeze-fracture replicas. J. Electron Microsc., 36: 283-293, 1987.

24) Takahashi, K., Kishi, Y. and Kim, S.: A scanning electron microscope study of the blood vessels of dog pulp using corrosion resin casts. J. Endodontics, 8: 131-135, 1982.

25) Takuma, S. and Nagai, N.: Ultrastructure of rat odontoblasts in various stages of their development and maturation. Archs. Oral Biol., 16: 993-1011, 1971.

26) Taniguchi, Y., Ohta, Y. and Tajiri, S.: New improved method for injection of acrylic resin. Okajimas Folia Anat. Jpn., 24: 259-267, 1952.

27) Taniguchi, Y., Ohta, Y., Tajiri, S., Okano, H. and Hanai, H.: Supplement to new improved method for injection of acrylic resin. Okajimas Folia Anat. Jpn., 27: 401-406, 1955. 


\section{PLATES}




\section{Explanation of figures}

\section{Plate I}

Fig. 1. 19-day embryo.

Sagittal semi-thin section of the dental papilla (DP). Capillaries (arrows) are observed in the inner region of the dental papilla and appear to have no relation to the mesenchymal cells (MC) situated in close proximity to the inner enamel epithelium (IEE). EO: enamel organ. Toluidine blue stain. $\times 200$.

Fig. 2. 19-day embryo.

The terminal pulpal vessels form a coarse and flattened network consisting of thick capillaries. Two pulpal horns are prominent. C: central pulpal horn. D: distal pulpal horn. 


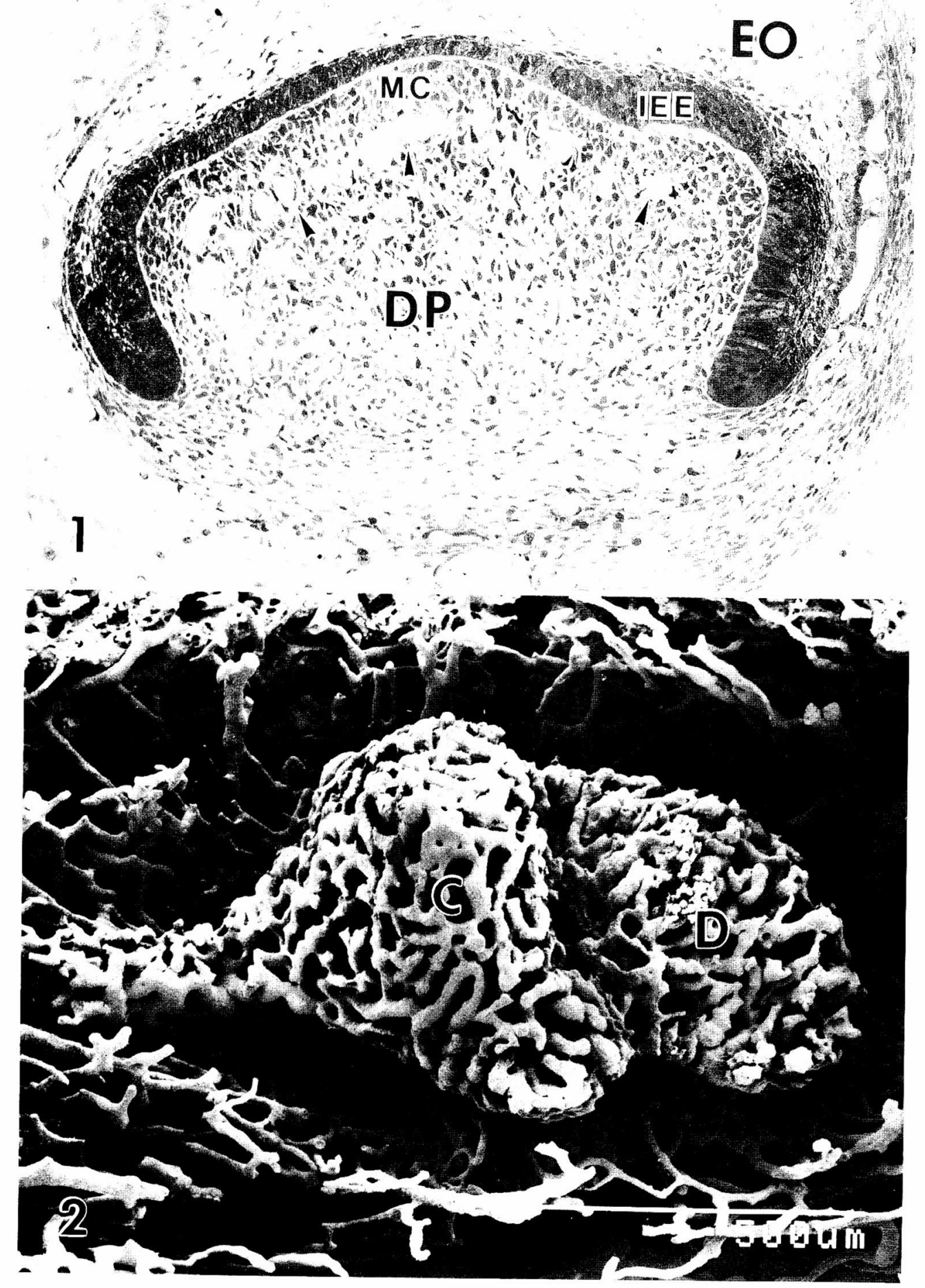




\section{Plate II}

Fig. 3. 21-day embryo.

The inner enamel epithelium and mesenchymal cells differentiate into ameloblasts (AB) and odontoblasts (OD), but no deposition of organic substances has yet started. The terminal pulpal capillaries (arrows) are situated in the subodontoblastic zone. DP: dental papilla. Toluidine blue stain. $\times 400$.

Fig. 4. 21-day embryo.

Five pulpal horns can be clearly recognized. The terminal network is dense and the capillaries are thinner than in the 19-day embryo. C: central pulpal horn, D: distal pulpal horn, M: mesial pulpal horn, ML: mesio-lingual pulpal horn, DL: disto-lingual pulpal horn. 


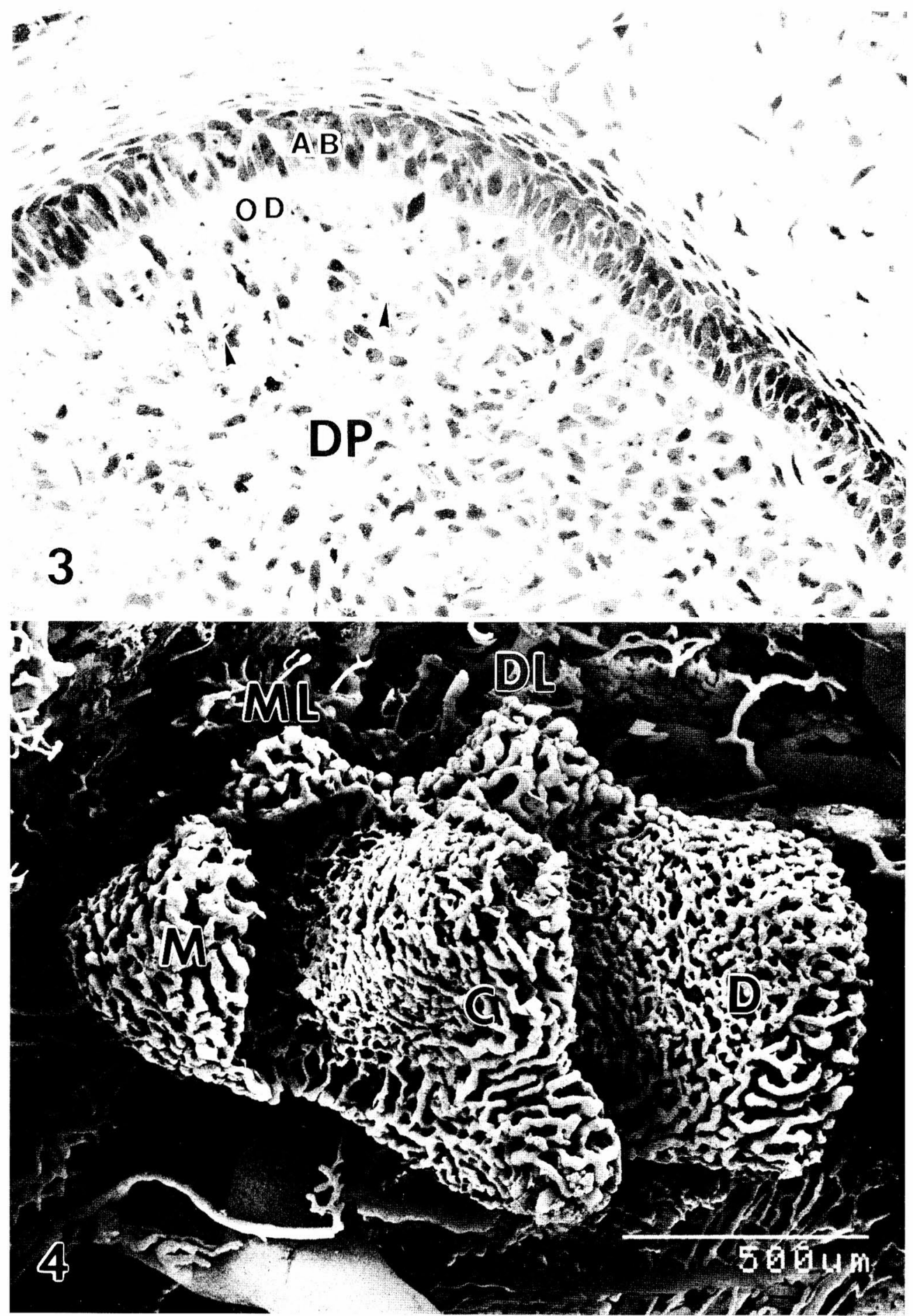




\section{Plate III}

Fig. 5. 1st day after birth.

Dentinogenesis and amelogenesis have already commenced in the cuspal region. The terminal pulpal capillaries (arrows) begin to invade the odontoblastic layer. AB: ameloblast, OD: odontoblast. Toluidine blue stain. $\times 200$.

Fig. 6. 1st day after birth.

The arterioles, after branching out a few times near the surface of the dental pulp, proceed to the terminal pulpal capillaries. The surface of the vascular network is irregular due to many low capillary loops towards the predentin. The capillaries are thinner (about $10 \mu \mathrm{m}$ ) than in the 21-day embryo. 


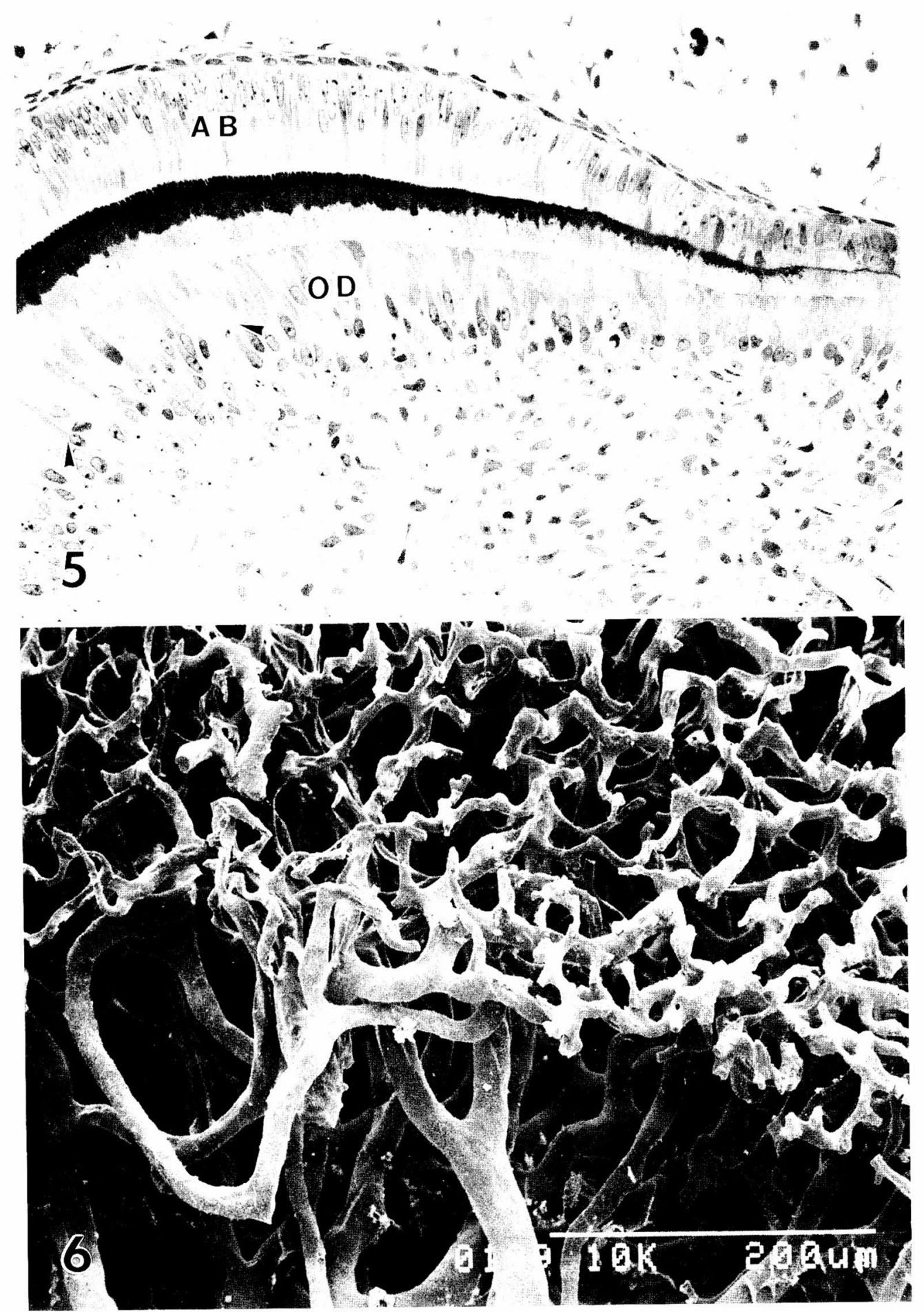




\section{Plate IV}

Fig. 7. 5 days after birth.

The terminal pulpal capillaries (arrows) are located in the odontoblastic layer (OD), about $5 \mu \mathrm{m}$ from the predentin (PD). E: enamel, D: dentin. Toluidine blue stain. $\times 400$.

Fig. 8. 5 days after birth.

The vascular network consisting of thin capillaries is dense and flattened. 

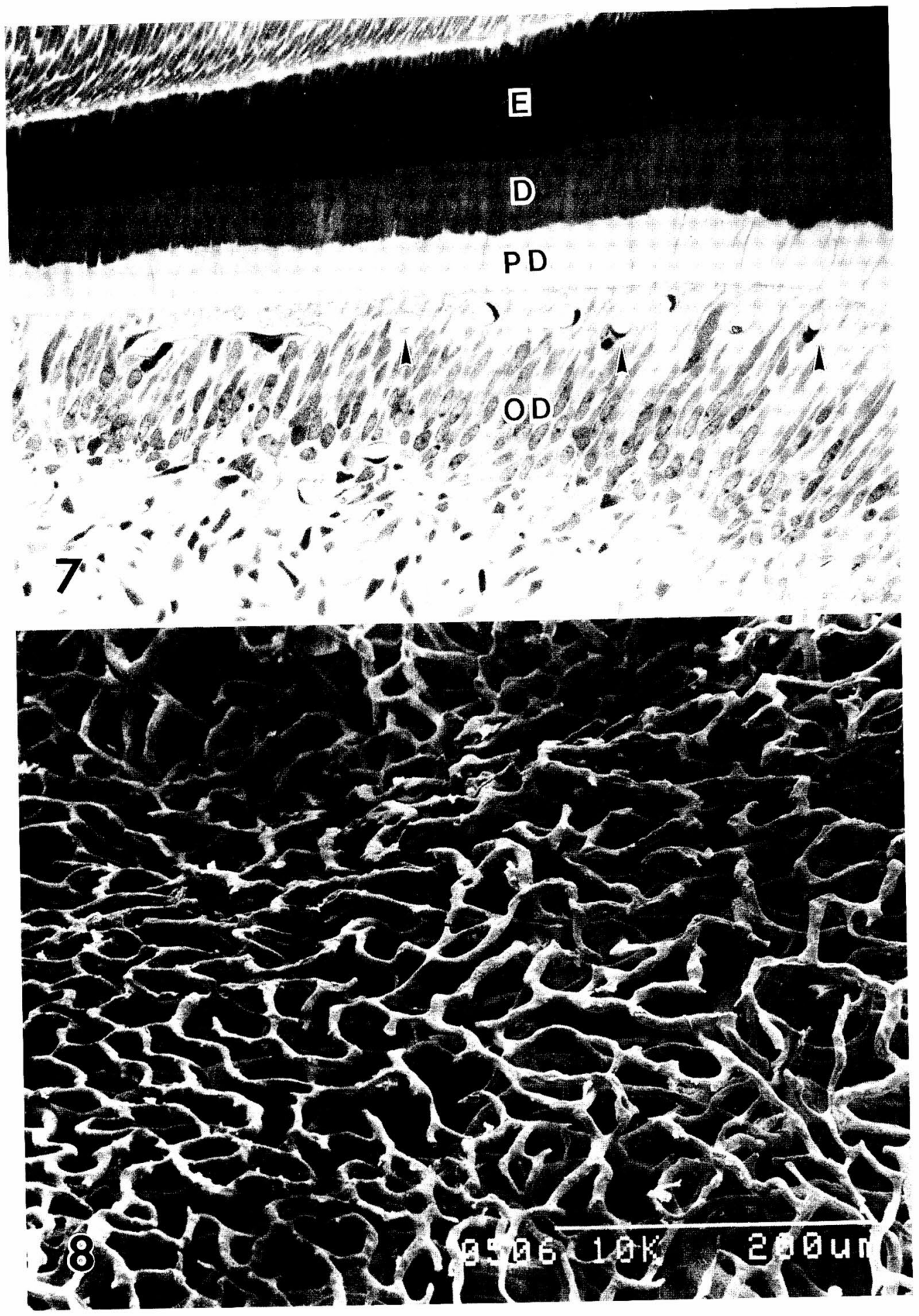


\section{Plate V}

Fig. 9. 21 days after birth.

The shape of the vascular network and the diameter of the capillaries are similar to those at 5 days after birth, but the density of the network is apparently higher than that at 5 days.

Fig. 10. 21 days after birth.

Sectioned surface of Fig. 9. The arterioles, after branching out a few times near the surface of the dental pulp, proceed to the terminal pulpal capillaries. A three-layered structure cannot be identified. 
Plate V

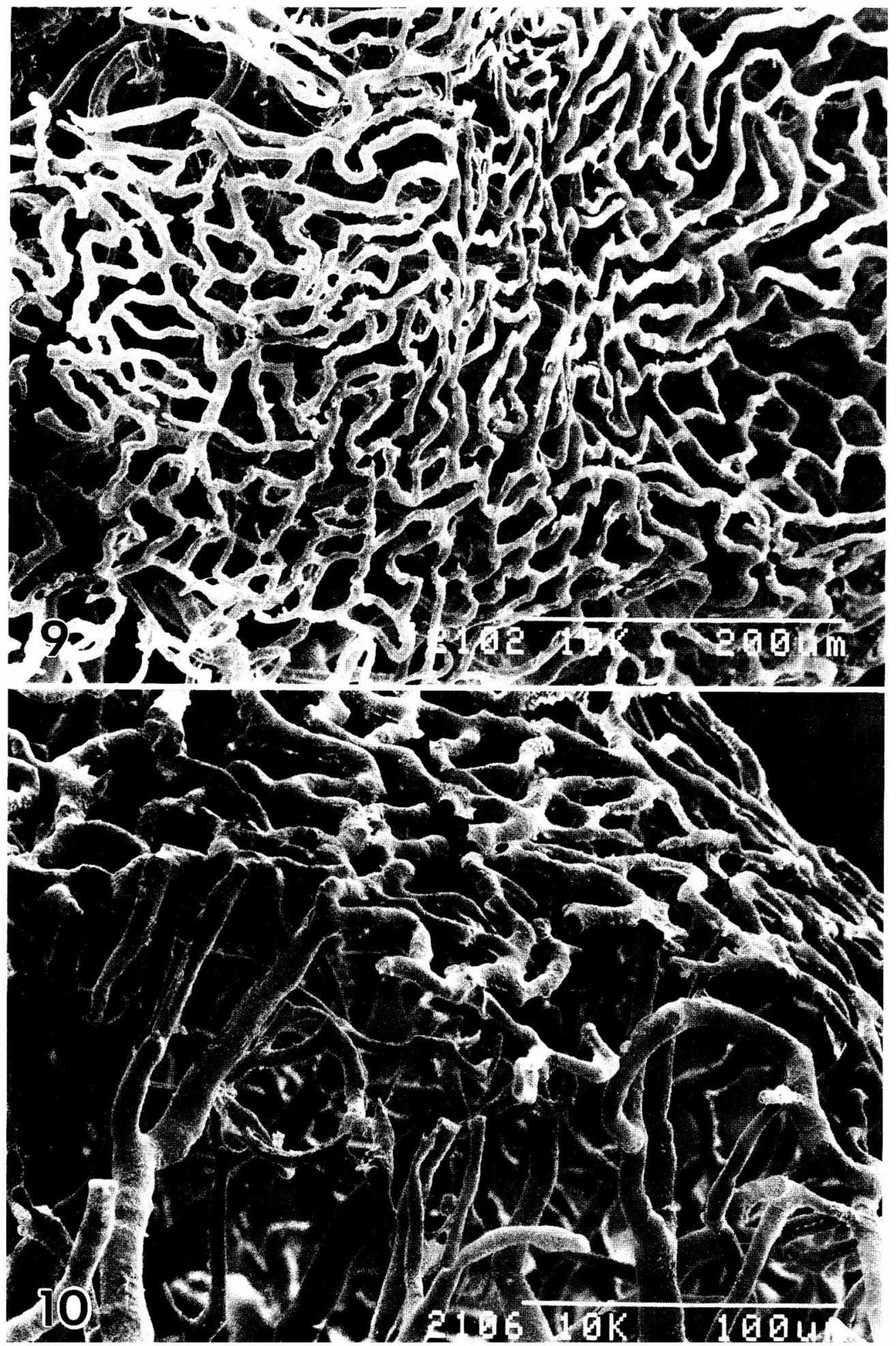

